\title{
Pattern-Specific Associative Long-Term Potentiation Induced by a Sleep Spindle-Related Spike Train
}

\author{
Mario Rosanova and Daniel Ulrich \\ Department of Physiology, University of Bern, 3012 Bern, Switzerland
}

Spindles are non-rapid eye movement (non-REM) sleep EEG rhythms $(7-14 \mathrm{~Hz})$ that occur independently or in association with slow oscillations $(0.6-0.8 \mathrm{~Hz})$. Despite their proposed function in learning and memory, their role in synaptic plasticity is essentially unknown. We studied the ability of a neuronal firing pattern underlying spindles in vivo to induce synaptic plasticity in neocortical pyramidal cells in vitro. A spindle stimulation pattern (SSP) was extracted from a slow oscillation upstate that was recorded in a cat anesthetized with ketamine-xylazine, which is known to induce a sleep-like state. To mimic the recurrence of spindles grouped by the slow oscillation, the SSP was repeated every $1.5 \mathrm{~s}(0.6 \mathrm{~Hz})$. Whole-cell patch-clamp recordings were obtained from layer $\mathrm{V}$ pyramidal cells of rat somatosensory cortex with infrared videomicroscopy, and composite EPSPs were evoked within layers II-III. Trains of EPSPs and action potentials simultaneously triggered by the SSP induced an NMDA receptor-dependent short-term potentiation (STP) and an L-type $\mathrm{Ca}^{2+}$ channel-dependent long-term potentiation (LTP). The number of spindle sequences affected the amount of STP-LTP. In contrast, spindle trains of EPSPs alone led to long-term depression. LTP was not consistently induced by a regular firing pattern, a mirrored SSP, or a randomized SSP; however, a synthetic spindle pattern consisting of repetitive spike bursts at $10 \mathrm{~Hz}$ reliably induced STP-LTP. Our results show that spindle-associated spike discharges are efficient in modifying excitatory neocortical synapses according to a Hebbian rule. This is in support of a role for sleep spindles in memory consolidation.

Key words: memory; learning; cortex; plasticity; pyramidal cell; non-REM

\section{Introduction}

An increasing amount of experimental evidence suggests that sleep is important for learning, memory consolidation, and development (Frank et al., 2001; Hobson and Pace-Schott, 2002; Walker and Stickgold, 2004). Sleep consists of alternating sequences of non-rapid eye movement (non-REM) and REM sleep episodes. REM sleep has been considered the prime mechanism for learning and memory consolidation. More recent studies (Gais et al., 2000; Mednick et al., 2002; Walker et al., 2002; Peigneux et al., 2004), however, have discovered an important role for non-REM sleep, which is characterized by slow $(0.1-14 \mathrm{~Hz})$ and high-amplitude oscillations and accounts for the majority of total sleep time. Indeed, it has been shown that the amount of slow oscillations $(0.6-0.8 \mathrm{~Hz})$ and sleep spindles $(7-14 \mathrm{~Hz})$, two EEG hallmarks of non-REM sleep, is increased after motor learning or declarative memory tasks, respectively (Gais et al., 2002; Huber et al., 2004).

During the early stages of sleep, spindles arise as sporadic events in the thalamus and are transmitted to the cortex. An observed temporal correlation of spindles and hippocampal

Received March 31, 2005; revised Aug. 19, 2005; accepted Aug. 19, 2005.

This work was supported by the Swiss National Science Foundation. The in vivo data were obtained by M.R. in the laboratory of Dr. I. Timofeev (University Laval, Quebec, Canada), supported by the Canadian Institutes of Health Research. We thank Drs. S. Fusi and M. Larkum for critical comments on this manuscript.

Correspondence should be addressed to Daniel Ulrich, Department of Physiology, University of Bern, 3012 Bern, Switzerland. E-mail: ulrich@pyl.unibe.ch.

DOI:10.1523/JNEUROSCI.2149-05.2005

Copyright $\odot 2005$ Society for Neuroscience $\quad$ 0270-6474/05/259398-08\$15.00/0 sharp-wave ripples is thought to reflect a hippocampocortical and corticohippocampal information transfer that is probably associated with memory formation (Siapas and Wilson, 1998; Sirota et al., 2003). As sleep deepens, the EEG is dominated progressively by the slow oscillation (Steriade et al., 1993a,b,c; Achermann and Borbély, 1997), which is produced by the alternation of depolarized (up or active) and hyperpolarized (down or silent) states (Steriade et al., 1993a, 2001). During the downstate, spike firing and synaptic activities are both depressed, whereas during the upstate, cortical neurons are firing synchronously within large areas (see Fig. 1) (Steriade et al., 1994; Amzica and Steriade, 1995; Destexhe et al., 1999). In humans, the slow oscillation is a traveling wave that periodically sweeps the cortex (Massimini et al., 2004) and is able to trigger and group the thalamic spindles (Amzica and Steriade, 1997; Mölle et al., 2002, 2004). This pacemaking of sleep spindles is reflected in animal recordings from cortex, where local field, multiunit, and intracellular traces show spindle oscillations starting just after the beginning of the upstate that are being sustained by highly synchronous and specific firing patterns (see Fig. 1) (Contreras and Steriade, 1995, 1996; Destexhe et al., 1999).

It is well known that synapses can undergo activity-dependent changes on different time scales. In particular, long-term potentiation (LTP) and long-term depression (LTD), which are longlasting increases and reductions, respectively, in synaptic strength, are considered important cellular mechanisms underlying learning and memory (Rioult-Pedotti et al., 2000). It has been proposed previously that the recurrent and coherent neu- 
ronal activities occurring during the slow oscillation and sleep spindles act as a gateway for the induction of synaptic plasticity (Steriade et al., 1993c; Sejnowski and Destexhe, 2000; Benington and Frank, 2003; Steriade and Timofeev, 2003) and memory consolidation (Buzsáki, 1998); however, although sleep spindles have been shown to enhance the responsiveness of cortical neurons (Castro-Alamancos and Connors, 1996; Bazhenov et al., 1998; Steriade et al., 1998; Timofeev et al., 2002), their impact on synaptic plasticity remains essentially unknown.

\section{Materials and Methods}

Tissue preparation and electrophysiology. Parasagittal slices of somatosensory cortex, $300 \mu \mathrm{m}$ thick, were prepared from 3-week-old Wistar rats at $4^{\circ} \mathrm{C}$ and incubated at $35^{\circ} \mathrm{C}$ in standard artificial CSF containing the following (in mM): $125 \mathrm{NaCl}, 1.25 \mathrm{NaH}_{2} \mathrm{PO}_{4}, 25 \mathrm{NaHCO}_{3}, 2.5 \mathrm{KCl}, 1$ $\mathrm{MgCl}_{2}, 2 \mathrm{CaCl}_{2}$, and 19 glucose, equilibrated with $5 \% \mathrm{CO}_{2}-95 \% \mathrm{O}_{2}$. The animal handling procedures were approved by our local animal care committee (Veterinary Services, Office of Agriculture, Bern, Switzerland). Patch pipettes (series resistance, 6-8 M 2 ) were filled with $130 \mathrm{~mm}$ K-gluconate, $10 \mathrm{~mm} \mathrm{NaCl}$, 0.1 mm EGTA, 10 mm HEPES, 5 mM ATP, and $2 \mu \mathrm{M}$ picrotoxin. Whole-cell current-clamp recordings were obtained from visually identified layer $\mathrm{V}$ pyramidal neurons in bridge mode (Stuart et al., 1993) by means of an Axoprobe 1A amplifier (Molecular Devices, Union City, CA), low-pass filtered at $1 \mathrm{kHz}$, and digitized at $3 \mathrm{kHz}$ with a Labmaster TL-1 A/D converter (Scientific Solutions, Solon, OH). Only regular spiking cells with a stable membrane potential below -60 $\mathrm{mV}$ (average, $-68 \pm 4.5 \mathrm{mV}$ ) were included in the database $(n=122)$, and a liquid junction potential of $-10 \mathrm{mV}$ was left uncorrected. Composite EPSPs were evoked by brief extracellular voltage pulses $(1 \mathrm{~ms}$; $20-80 \mathrm{~V}$ ) through bipolar metal electrodes placed laterally in layers IIIII, at a distance of $\sim 300-600 \mu \mathrm{m}$. Single action potentials were elicited by injecting brief depolarizing current pulses $(2 \mathrm{~ms}, 3 \mathrm{nA})$ into the soma.

Stimulation patterns. The spindle stimulation pattern (SSP) was derived from an intracellular recording in the cat primary somatosensory cortex in vivo under ketamine-xylazine anesthesia (Rosanova and Timofeev, 2005). The SSP was extracted from the timing of action potentials fired by an infragranular $(\sim 1200 \mu \mathrm{m}$ deep $)$ regular spiking cell during an entire slow oscillation upstate starting with a spindle sequence (Fig. 1). The SSP had a duration of $728 \mathrm{~ms}$ and contained 22 spikes (mean firing rate, $\sim 30 \mathrm{~Hz}$ ) that were grouped initially in $\sim 10 \mathrm{~Hz}$ rhythmic bursts followed by a tonic tail of decreasing frequency (Steriade et al., 1998). A randomized SSP was obtained by reshuffling the interspike intervals of the original SSP. The mirrored SSP consisted of the SSP interspike interval sequence in reverse temporal order. The mean pattern was a stimulation sequence with the same duration, the same number of stimuli (22), and the same mean firing rate as the SSP, but a constant interstimulus interval. The synthetic spindle pattern consisted of three $100 \mathrm{~Hz}$ spike quadruplets separated by an interval of $100 \mathrm{~ms}$.

Experimental design and data analysis. In control conditions, composite EPSPs were evoked for at least $5 \mathrm{~min}$ at $0.1 \mathrm{~Hz}$ (30 episodes). The conditioning protocol consisted of 30 repetitions with one of the firing patterns above, repeated every $1.5 \mathrm{~s}(0.6 \mathrm{~Hz})$ to trigger EPSPs or action potentials, or both. Successive conditioned EPSPs were elicited for 30 min at $0.1 \mathrm{~Hz}$. EPSP changes were determined by comparing, for every cell, the mean amplitudes of 30 EPSPs in control and after the conditioning protocol. Statistical comparison was done with the Mann-Whitney $U$ test $(p=0.05)$. All drugs were from Tocris (Bristol, UK) and bath applied, unless stated otherwise.

\section{Results}

SSP-induced short- and long-term synaptic potentiation Composite EPSPs were evoked within layers II-III by extracellular stimuli repeated at $0.1 \mathrm{~Hz}$ and recorded in visually identified layer $\mathrm{V}$ pyramidal neurons in whole-cell current-clamp mode. The stimulus intensity was adjusted to ensure that individual EPSPs and trains of EPSPs always remained subthreshold for action potential generation. Picrotoxin $(2 \mu \mathrm{M})$ was added to the

\section{A, in vivo}
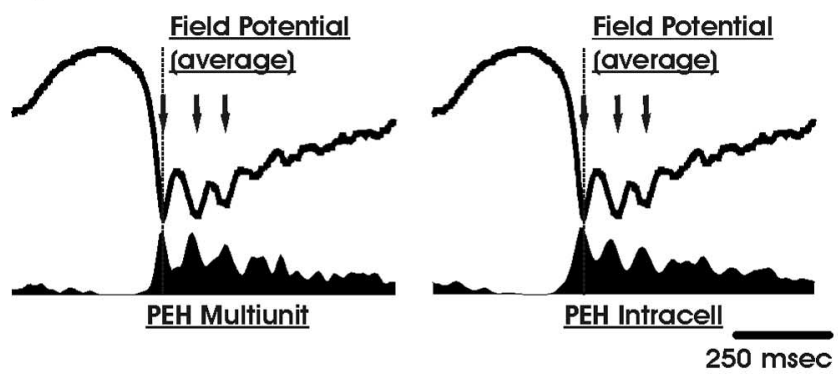

\section{$\mathrm{B}$, in vivo}

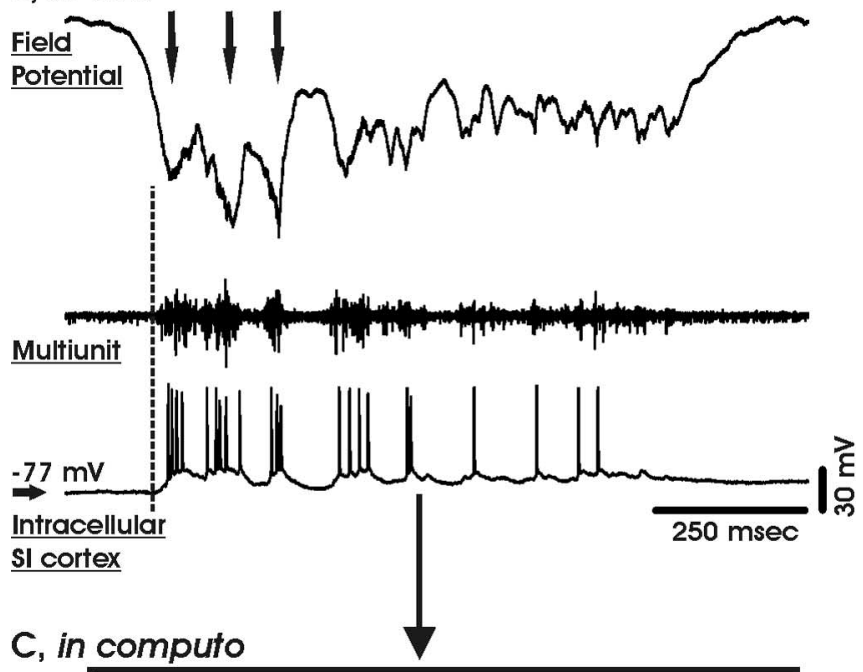

Spindle Stimulus Pattern (SSP)

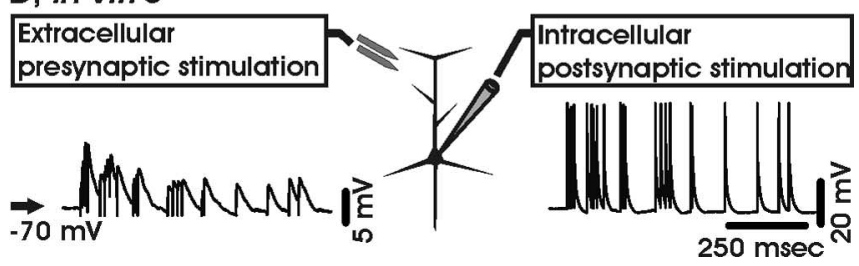

Figure 1. The spindle stimulus pattern. $\boldsymbol{A}$, Average local field potentials and peri-event histograms (PEH) of multiunit (left) and intracellular (right) spike activity simultaneously obtained in vivo from the primary somatosensory (SI) cortex of a cat anesthetized with ketaminexylazine. The graphs are aligned to the onset (dashed line) of three spindle oscillations (arrows). $\boldsymbol{B}$, Individual local field, multiunit, and intracellular recordings from the same experiment as in $\boldsymbol{A}$. The selected segment shows an upstate emerging from the depolarizing phase of the slow oscillation cycle (vertical dashed line) that contains a spindle sequence (three oscillations at 10 $\mathrm{Hz}$ indicated by arrows). Note that the cell is bursting concomitantly with the spindle oscillations. C, Raster plot derived from the SSP. D, Sample trains of EPSPS (left) and action potentials (right) evoked by a single SSP.

pipette solution to block $\mathrm{GABA}_{\mathrm{A}}$ receptor-mediated synaptic inhibition. A series of 30 EPSPs was obtained in control conditions. During the conditioning protocol, EPSPs and action potentials in the postsynaptic cell were elicited simultaneously by a sequence of stimuli derived from an SSP (see Materials and Methods) (Fig. $2 A, B)$. The instantaneous frequency plot of the SSP revealed a decelerating firing rate in agreement with the waning discharge 
pattern of sleep spindles (Fig. 2B) $(r=$ $-0.5 ; p<0.03$ ) (Contreras and Steriade, 1996). The SSP was repeated 30 times every $0.6 \mathrm{~s}$ to mimic the grouping of spindles by the slow $(0.6-0.8 \mathrm{~Hz})$ oscillation in vivo. After conditioning, EPSPs were elicited again at $0.1 \mathrm{~Hz}$ for $>30 \mathrm{~min}$. Comparison of EPSP amplitudes in control, shortly after conditioning ( $\sim 5 \mathrm{~min})$, and $>30$ min later revealed a short-term potentiation (STP) followed by an LTP (Fig. $2 C, D)$. We observed STP and LTP in 11 and 9 of 14 cells, respectively (STP, $164 \pm$ 22\%; LTP, $125 \pm 8 \%$; mean \pm SEM; $p<$ 0.01 ) (Fig. 2). No linear correlation was found between the amplitude of the control EPSP $(0.8-8 \mathrm{mV})$ and the magnitude of STP and LTP, or between the magnitude of STP and LTP (data not shown). We conclude that the SSP-induced STP-LTP did not depend on the size of the EPSP. We also found, in a separate series of experiments, that LTP could still be induced without blocking $\mathrm{GABA}_{\mathrm{A}}$ receptors (LTP, $114 \pm 3 \% ; n=6 ; p<0.03$ ) (data not shown), thus demonstrating that the SSP was also effective, with the $\mathrm{GABA}_{\mathrm{A}}$ ergic synaptic inhibition left intact. Our results suggest that cells that fire synchronously during spindles strengthen their synaptic connections.

To test whether the variable number of spindles seen in vivo has a functional significance, we systematically varied the number of conditioning SSP trains. STP was significant for 20 and 30 trains $\left(\mathrm{STP}_{20}, 123 \pm 9 \% ; n=10 ; p<0.03\right)$, whereas LTP was seen only for 30 repetitions (Fig. 3). Both STP and LTP vanished with 40 or 50 SSP applications (Fig. 3). This suggests an optimal number of SSP trains for the induction of short- and long-term synaptic enhancements.

Physiological properties of SSP-induced synaptic plasticity To test whether SSP-induced STP-LTP is associative, the standard conditioning protocol was used to separately trigger EPSPs or postsynaptic action potentials (Fig. 4). With the SSP applied only postsynaptically, EPSPs were reduced for the remainder of the recordings ( $87 \pm 5 \% ; n=7$ ) (Fig. $4 A$ ); however, this depression was not significant compared with control experiments in which EPSPs were elicited over the same time interval without conditioning ( $95 \pm 5 \% ; n=7 ; p>0.2$ ). In contrast, when 30 trains of SSP were applied only presynaptically, EPSPs were significantly depressed for the rest of the recordings ( $62 \pm 9 \%$; $n=$ $9 ; p<0.03$ ) (Fig. $4 B$ ). We thus conclude that the STP-LTP elicited with the standard SSP protocol is associative, whereas presynaptic activity alone leads to LTD.

\section{Cellular mechanisms of SSP-triggered STP-LTP}

To elucidate the physiological mechanisms underlying the SSPinduced STP-LTP, we repeated the standard conditioning protocol in the presence of $50 \mu \mathrm{M}$ DL-2-amino-5-phosphonovalerate (DL-APV) to block NMDA receptors, which are glutamate receptor subtypes frequently involved in synaptic plasticity. Surprisingly, with the NMDA receptors blocked, LTP was still significant $(118 \pm 7 \% ; n=12 ; p<0.04)$ (Fig. $5 A$ ), whereas STP was abol-

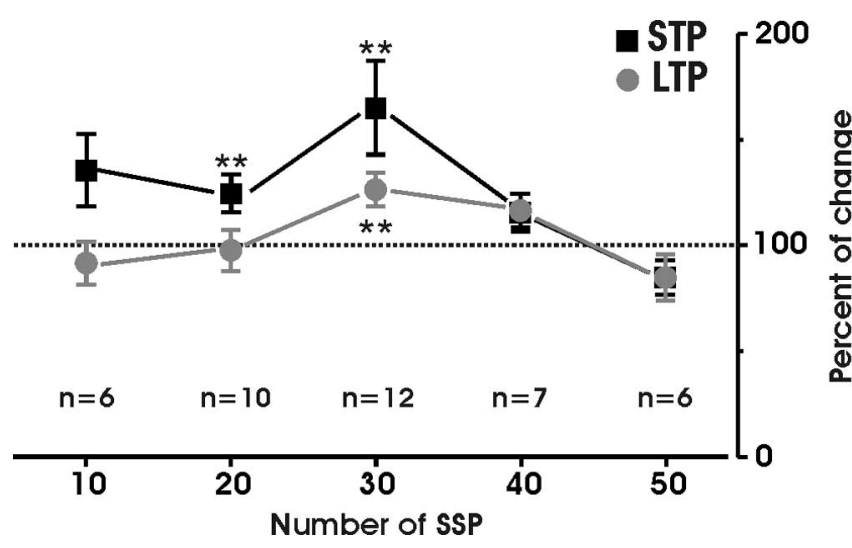

Figure 3. STP and LTP depend on the number of SSPS. Relative magnitude (mean \pm SEM) of STP (black squares) and LTP (gray circles) versus the number of conditioning SSPs is shown. Note that only 30 repetitions were able to induce a statistically significant LTP. ${ }^{* *} p<0.03$.

ished. In another set of experiments, L-type $\mathrm{Ca}^{2+}$ channels, which are known to participate in non-NMDA receptordependent synaptic plasticity, were blocked with nifedipine (10 $\mu \mathrm{M})$. With the L-type $\mathrm{Ca}^{2+}$ channels blocked, LTP was now annihilated $(107 \pm 13 \% ; n=9 ; p>0.5)$ (Fig. $5 B$ ), whereas STP was still intact $(161 \pm 24 \% ; p<0.05)$. Finally, with coapplication of DL-APV and nifedipine, no significant short- or long-term synaptic effects remained (Fig. $5 C$ ). We thus conclude that SSPinduced STP is mediated mainly by NMDA receptors, whereas LTP depends mostly on L-type $\mathrm{Ca}^{2+}$ channels.

\section{Specificity of the SSP}

To assess whether the induced synaptic changes were specific for spindle discharges, we repeated the standard pairing protocol 
A
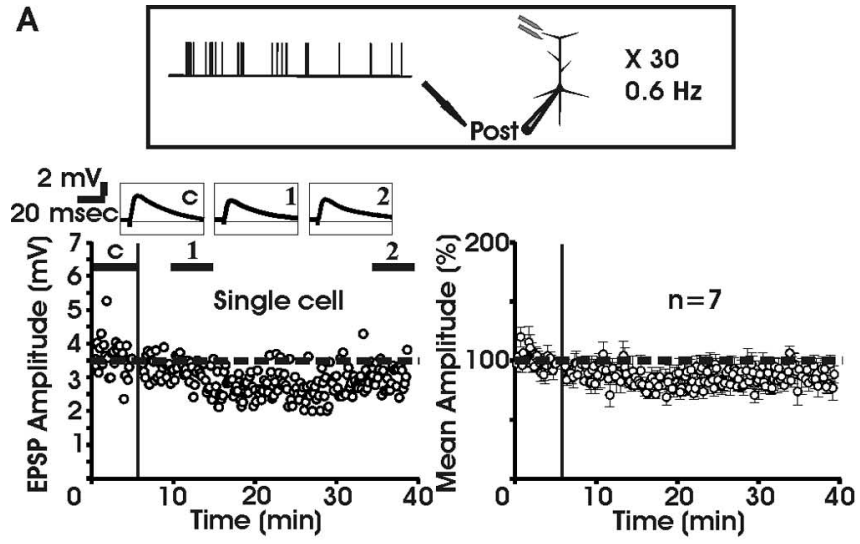

B
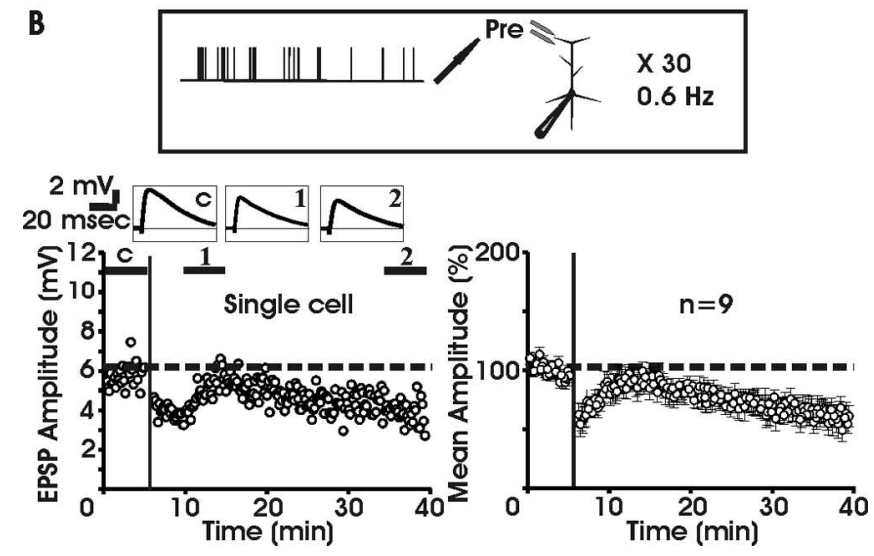

Figure 4. Associativity of SSP-induced STP and LTP. A, Left, Sample traces of averaged EPSPS (insets: control, 1, 2) and amplitude time series in control and after the conditioning protocol (vertical black bar). Only the postsynaptic cell was stimulated by the SSP $(30 X ; 0.6 \mathrm{~Hz})$. Right, Time course of the average EPSP amplitude ( \pm SEM; $n=7$ ). $\boldsymbol{B}$, Left, Sample EPSPs (insets: control, 1,2) and amplitude time series from an individual cell before and after a conditioning protocol with only presynaptic EPSPs triggered by the SSP (vertical black bar). Right, Time series of the average normalized ( $\pm S E M ; n=9$ ) EPSP amplitudes. Note that with presynaptic conditioning stimuli in isolation, there is a significant LTD. c, Control; Pre, presynaptic; Post, postsynaptic.

with a synthetic spindle pattern consisting of three spike quadruplets occurring at $100 \mathrm{~Hz}$ with an interburst interval of $100 \mathrm{~ms}$ (Fig. 6A). With this pattern, the pairing protocol led to significant STP $(132 \pm 8 \% ; n=7)$ and LTP $(136 \pm 8 \% ; p<0.02)$. In contrast, a regular spike pattern of a constant interspike interval of $33 \mathrm{~ms}$, which corresponds to the average interspike interval of the SSP, was inefficient in inducing LTP (Fig. 6B). Conditioning with the regular spike train induced only an STP $(113 \pm 5 \% ; n=$ $10 ; p<0.04)$ without leading to long-term synaptic modifications $(98 \pm 5 \% ; p>0.7$ ) (Fig. $6 B$ ). To investigate whether any irregular spike train was as efficient as the SSP in inducing STPLTP, the interspike intervals of the SSP were shuffled randomly (Fig. 7); however, the standard conditioning protocol with the shuffled SSP did not lead to any consistent synaptic modifications (Fig. 7). As a third test for the specificity of the SSP, the pairing protocol was repeated with a mirrored SSP sequence (see Materials and Methods) (Fig. 8). As with the regular and random sequences, the mirrored SSP did not lead to any significant longterm synaptic changes $(n=13)$ (Fig. $8 A)$. In a subpopulation of cells in which the mirrored SSP had no effect, a second conditioning protocol with the original SSP was still capable of inducing STP-LTP (STP, $150 \pm 8 \%$; LTP, $150 \pm 8 \% ; n=6 ; p<0.05$ ) (Fig. $8 B)$. The fraction of cells that underwent significant STP-LTP
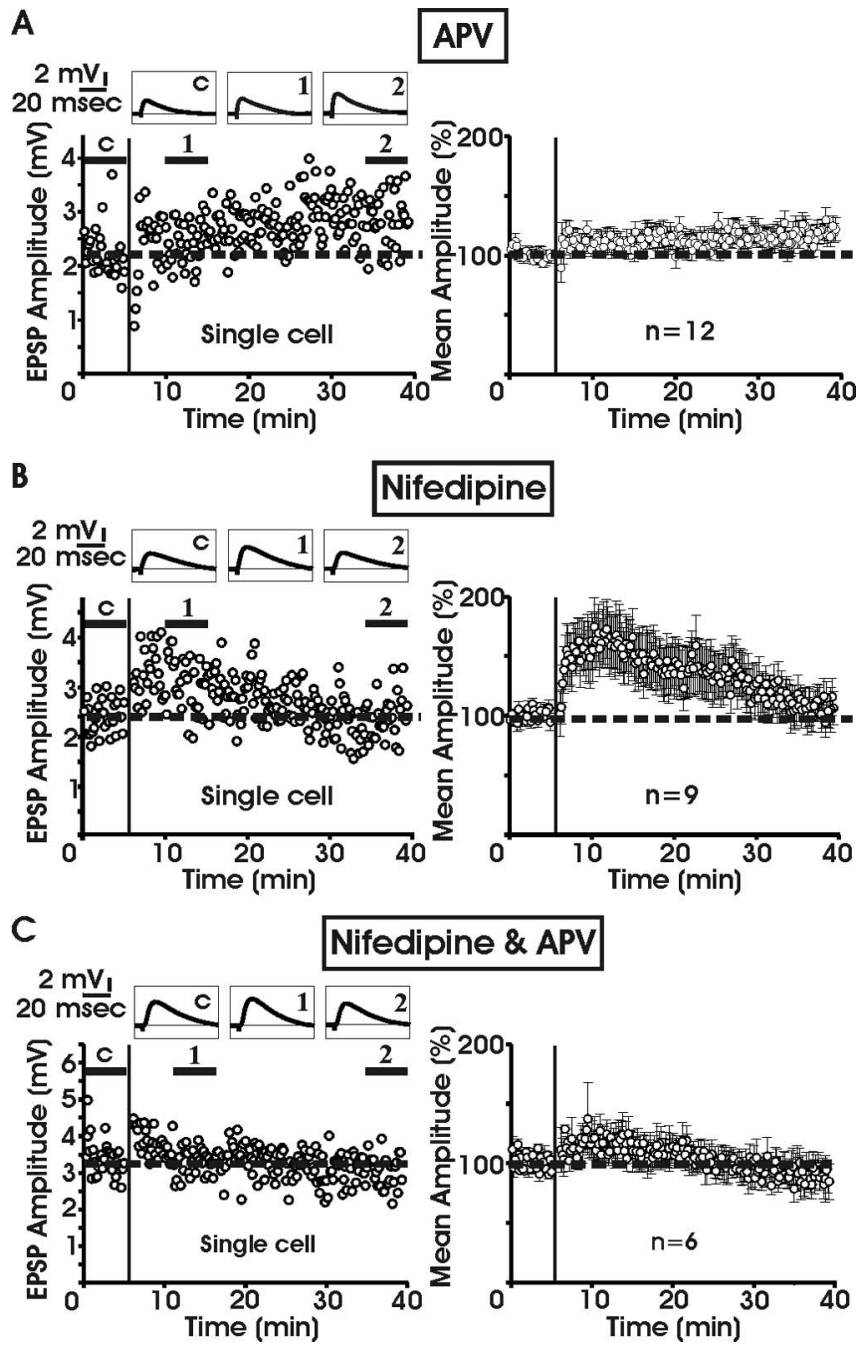

Figure 5. SSP-induced STP depends on NMDA receptors and LTP depends on L-type calcium channels. $\boldsymbol{A}$, Left, Sample traces (insets: control, 1, 2) and amplitude time course of EPSPs recorded before and after the SSP conditioning protocol (vertical black bar) in the presence of 50 $\mu \mathrm{M} \mathrm{DL}-A P V$. Right, Time series plot of the average normalized EPSP ( \pm SEM; $n=13$ ) in DL-APV. $\boldsymbol{B}$, Left, Sample EPSPs (insets: control, 1,2) and EPSP amplitude time series in the presence of 10 $\mu \mathrm{m}$ nifedipine. Right, Average time course of normalized EPSPs with nifedipine ( $\pm \mathrm{SEM} ; n=$ 9). C, Left, Sample EPSPs (insets: control, 1, 2) and EPSP amplitude time series in the presence of nifedipine and DL-APV. Right, Average time course of all normalized EPSPs with nifedipine and DL-APV ( \pm SEM; $n=6)$. c, Control.

has been summarized for the different conditioning patterns (Fig. 9), which were derived from the main template (compare Fig. 1). A pairwise comparison of each of the firing patterns versus the other three revealed that the fraction of cells that underwent robust LTP was significantly higher for the SSP (Fisher's exact test; $p<0.05$ ) (Fig. 9), thus demonstrating the superiority of this particular spike sequence. Similarly, STP-LTP was readily induced with another SSP stimulation pattern (data not shown). We concluded that spindle sequences consisting of decelerating rhythmic burst discharges are efficient in inducing short- and long-term synaptic potentiation.

\section{Discussion}

Despite their proposed role in memory consolidation, the influences of neural discharges associated with deep sleep on neocortical synapses are essentially unknown. Here we show that a natural firing pattern recorded in vivo during sleep spindles was able 
A

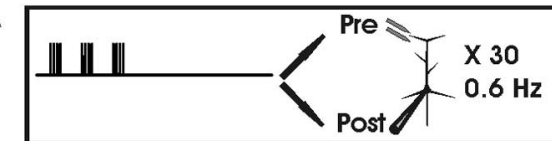

$20 \mathrm{msec} \sim r \quad r \quad 2$
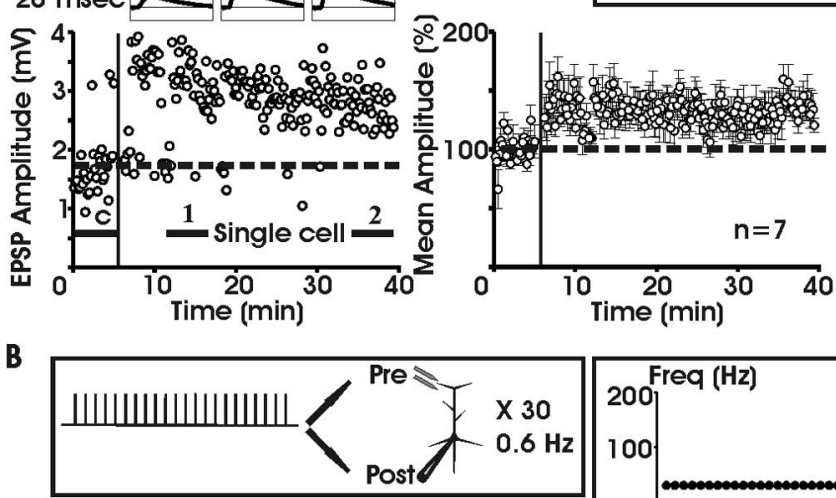

$2 \mathrm{mV}$
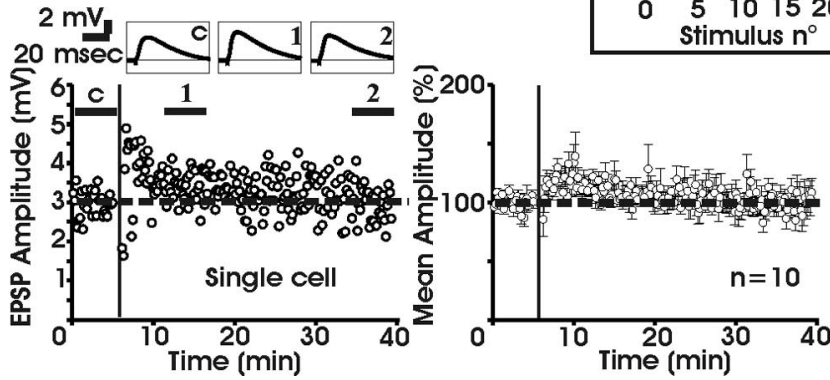

Figure 6. Rhythmic discharges favor STP-LTP. A, Left, Sample EPSPs (insets: control, 1, 2) and EPSP amplitude time course from an individual cell conditioned by three high-frequency (Freq) spike bursts (vertical black bar). Right, Time course of the averaged normalized EPSPs ( \pm SEM; $n=7$ ). $\boldsymbol{B}$, Left, Sample EPSPs (insets: control, 1, 2) and EPSP amplitude time course from an individual cell with a regular spike train as the conditioning stimulus (vertical blackbar). Right, Time course of the averaged normalized EPSPs ( \pm SEM; $n=10)$. Pre, Presynaptic; Post, postsynaptic; c, control.

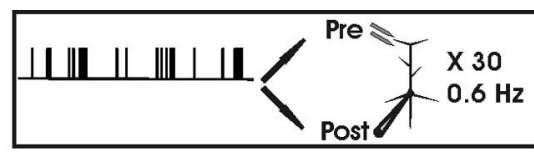

$2 \mathrm{mV}$
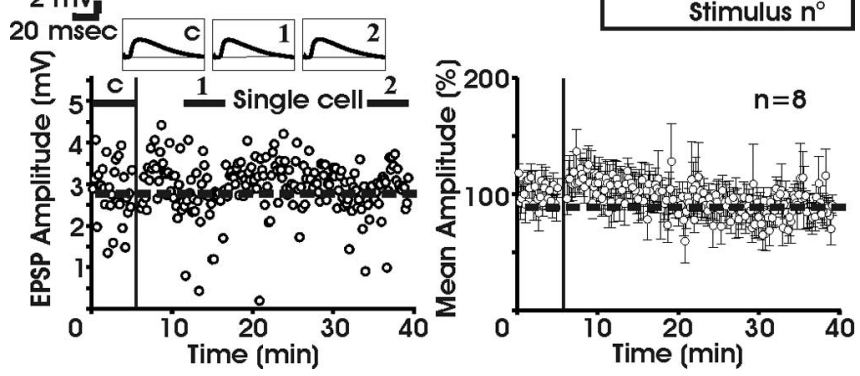

Figure 7. STP-LTP are pattern sensitive. Left, Sample EPSPs (insets: control, 1, 2) and EPSP amplitude time course before and after conditioning with a shuffled SSP (top left panel). Top right panel, Instantaneous frequency (Freq) plot of the shuffled SSP fit with a straight line (dashed line; $r=0.15 ; p>0.5$ ). Right, Average time course of normalized EPSPs conditioned with the shuffled SSP ( \pm SEM; $n=8$ ). Pre, Presynaptic; Post, postsynaptic; c, control.

to induce associative STP-LTP of EPSPs in layer V pyramidal cells in vitro. The effects were specific to this stimulation pattern; a comparable regular spike train, a shuffled spindle pattern, and a mirrored spindle pattern were ineffective. Additionally, a generalized spindle pattern consisting of $10 \mathrm{~Hz}$ rhythmic bursts also
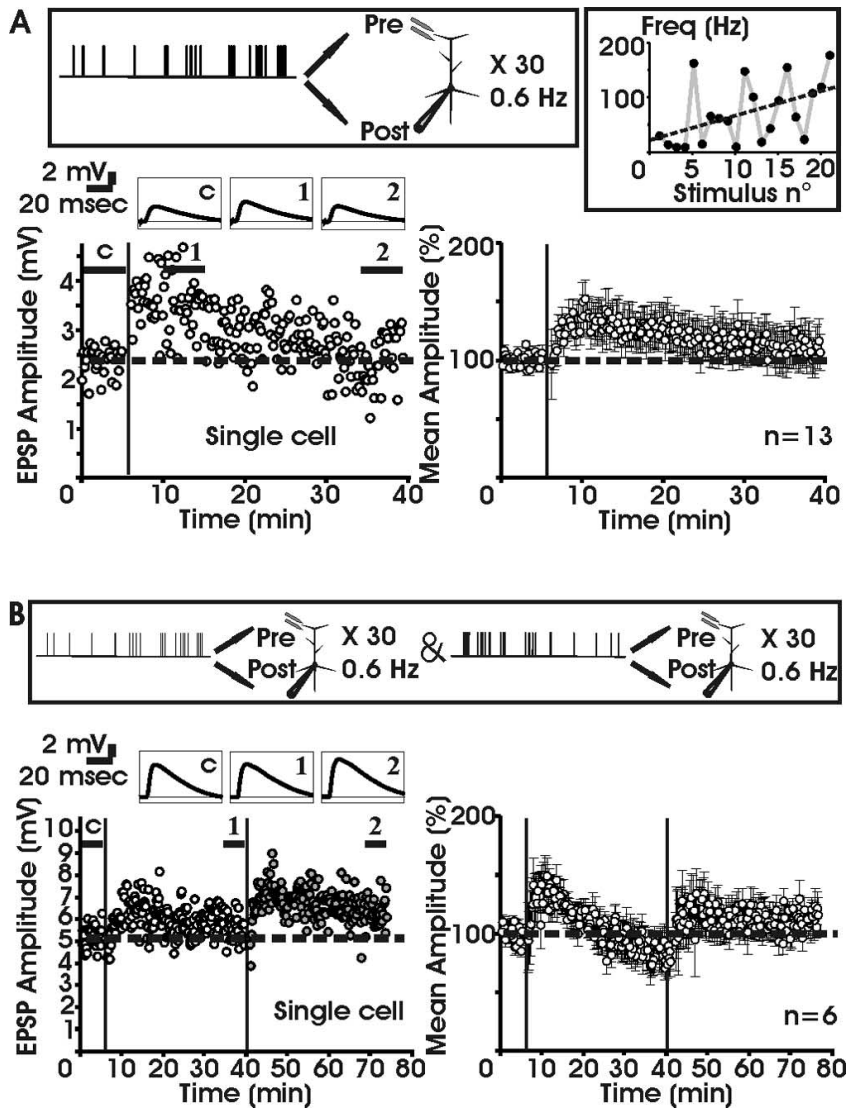

Figure 8. SSP pattern specificity. $\boldsymbol{A}$, Left, Sample EPSPs (insets: control, 1, 2) and EPSP amplitude time course from an individual cell before and after conditioning with the mirrored SSP (vertical black bar). Right, Amplitude time course of the average normalized EPSPS ( \pm SEM; $n=13$ ). Top panels, Experimental arrangement and instantaneous frequency (Freq) content of the mirrored SSP. The dashed line represents the linear fit to the data points $(r=0.5 ; p<0.03)$. $\boldsymbol{B}$, Left, Sample EPSPs (insets: control, 1,2) and amplitude time course before and after conditioning with the mirrored SSP (white circles) followed by a second conditioning with the original SSP (gray circles). Right, Amplitude time series of all normalized EPSPS ( \pm SEM; $n=6)$ that underwent the dual conditioning protocol. Pre, Presynaptic; Post, postsynaptic; c, control.

A

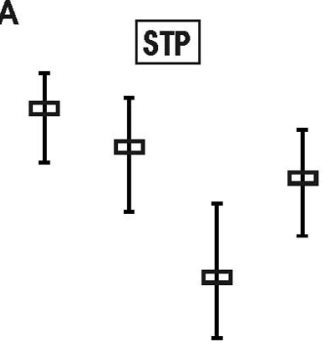

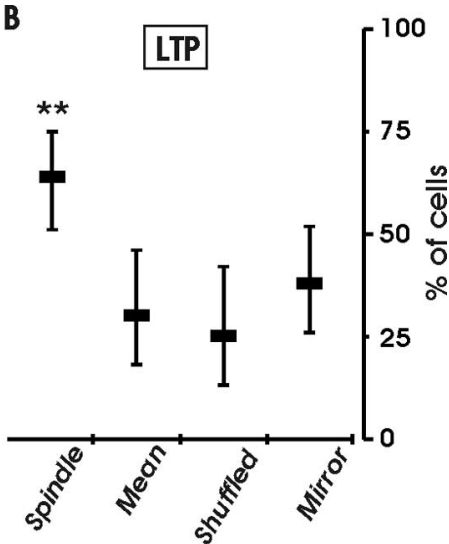

Stimulation pattern

\section{Stimulation pattern}

Figure 9. Efficacy of different firing patterns for STP-LTP induction. Summary bar plot of the fraction of cells (mean +1 SD confidence interval) that underwent significant STP $(\boldsymbol{A})$ or LTP $(\boldsymbol{B})$ for the different conditioning firing patterns. ${ }^{* *} p<0.05$ (Fisher's exact test).

induced STP-LTP. LTP required a certain number of SSP applications and activation of L-type $\mathrm{Ca}^{2+}$ channels. In contrast, STP was already evident for lower SSP reiterations and depended on NMDA receptors. Interestingly, both STP and LTP declined 
when the SSP pattern exceeded 30 reiterations. Nonassociative SSP conditioning led to LTD.

The simultaneous presynaptic and postsynaptic application of the SSP at $0.6 \mathrm{~Hz}$ was intended to mimic a reoccurring slowoscillation upstate containing a spindle sequence characteristic of slow-wave sleep (Fig. 1) (Contreras and Steriade, 1995, 1996; Destexhe et al., 1999). With this idealized experimental paradigm, STP-LTP was seen only when the SSP stimulus was applied simultaneously to trigger EPSPs and action potentials; otherwise, EPSPs were depressed. Therefore, both STP and LTP were associative, as required for a Hebbian process. This is in contrast to previous studies in which LTP induction by irregular spike trains did not require an explicit activation of the postsynaptic cells (Dobrunz and Stevens, 1999). STP-LTP likely arose from a strengthening of excitatory synapses, because $\mathrm{GABA}_{\mathrm{A}}$ receptors were blocked in most recordings by intracellular application of picrotoxin (Akaike et al., 1985). The NMDA receptor dependency of STP is in agreement with previous reports at cortical synapses (Malenka, 1991). STP can be converted to LTP by enhancing $\mathrm{Ca}^{2+}$ influx into the postsynaptic cell, presumably into dendritic compartments (Malenka, 1991). At least one form of LTP in cortical neurons is known to depend on L-type $\mathrm{Ca}^{2+}$ channels, which can act as an additional source of $\mathrm{Ca}^{2+}$ (Grover and Teyler, 1990). L-type $\mathrm{Ca}^{2+}$ channels are activated by action potentials that backpropagate into the dendrites (Markram et al., 1995), and the resulting rise in the intracellular $\mathrm{Ca}^{2+}$ concentration can be increased further by a coincident EPSP (Koester and Sakmann, 1998). This may explain why the SSP had to simultaneously trigger EPSPs and postsynaptic action potentials to successfully induce LTP. Indeed, during in vivo upstates, backpropagation of action potentials may be even more effective because spontaneous synaptic activity was shown to boost the retrograde action potentials and enhance the dendritic calcium influx (Waters and Helmchen, 2004). Our findings are also in line with those of Contreras et al. (1997), who showed previously that sleep spindles are likely to be associated with considerable dendritic $\mathrm{Ca}^{2+}$ influx. The efficacy of the SSP can likely be attributed to the initial burst discharges, which are a common feature of spindles, because a repetitive burst pattern also reliably induced STP-LTP (Fig. 6). This is in line with classic LTP protocols such as tetanic and theta burst stimuli, which also consist of high-frequency burst discharges; however, the pattern sensitivity of the SSP goes beyond these classic protocols (see below)

It has been shown previously that the high-frequency components of natural spike trains are efficiently backpropagated into the dendrites (Williams and Stuart, 2000), and presynaptic bursts may enhance the reliability of synaptic transmission (Williams and Stuart, 1999). This may explain the superiority of the SSP versus the regular spike train in inducing synaptic plasticity; however, the findings that the mirrored SSP and the shuffled SSP were inferior compared with the original SSP require an additional explanation. Different presynaptic firing patterns may lead to different EPSP summations (Dobrunz and Stevens, 1999) that eventually lead to particular concentration profiles of the intracellular $\mathrm{Ca}^{2+}$. Experimental and simulation studies have shown that key enzymes involved in synaptic plasticity are sensitive to the pattern of applied stimuli and the accompanying $\mathrm{Ca}^{2+}$ influx (DeKoninck and Schulman, 1998; Bhalla, 2002). The SSP is a complex sequence containing spike bursts and single action potentials arranged in a particular temporal sequence resulting from a particular state of the thalamocortical system. The SSP likely induces a complex spectrum of recently described synaptic plasticity phenomena, such as spike timing and firing mode- dependent changes in synaptic strength (Froemke and Dan, 2002; Birtoli and Ulrich, 2004). Overall, this result suggests that the mean frequency and the interval distribution are not sufficient parameters to characterize the impact of a particular spike pattern on synaptic plasticity; instead, the precise temporal order of interspike intervals has to be taken into account. This conclusion is in line with a recent theoretical study showing that the mechanisms leading to consolidation of synaptic plasticity should be sensitive to the firing pattern (Fusi, 2002). That this is a stochastic process (Fusi, 2002) is also supported by our data (Fig. 9), which show that the relative efficacy of the different firing patterns in inducing LTP is ultimately a probabilistic phenomenon.

When the SSP was applied only presynaptically, LTD was induced consistently, which is indicative of an anti-Hebbian mechanism, as shown previously (Artola et al., 1990). This is in line with the current idea of LTP and LTD being induced by strong and moderate depolarizations, respectively (Lisman, 1989), that are associated with a proportional rise in intracellular $\mathrm{Ca}^{2+}$.

There is growing evidence that non-REM sleep is a fundamental step in learning and memory processes. Learning induces an increase in spindle density (Gais et al., 2002; Clemens et al., 2005) and a local increase in the slow oscillations within the cortical areas that were likely involved in the learning (Huber et al., 2004). Although little is known about the precise cellular processes of this consolidation mechanism, our data support the following scenario. A slow oscillation upstate can be triggered by a few excitatory quantal events, which are likely to originate from recently potentiated synaptic connections within a network that has been lately involved in a particular task (Timofeev et al., 2000; Ribeiro et al., 2004). This cortical upstate is able to run a sequence of highly synchronous spindles that are known to occur more likely at previously potentiated synapses (Werk at al., 2005). These spindles will lead to further strengthening of connections between synchronously firing cells, according to a Hebbian rule; however, because the slow oscillation is a traveling wave (Massimini et al., 2004), only a limited number of cells are firing together in a certain time interval during a spindle. Connections between uncorrelated cells outside of the traveling wave will be weakened, according to an anti-Hebbian mechanism. This differential strengthening of synaptic connections may require repetitive bouts of spindle activity that could lead eventually to depotentiation (Villarreal et al., 2002). Although our data suggest an optimal number of spindle trains (Fig. 3), it remains to be investigated whether a comparable phenomenon exists in vivo and, if so, what functional role it would subserve. Because cells involved in the same task during wakefulness are known to strengthen their synaptic connections and vice versa (Rioult-Pedotti et al., 2000; Allen et al., 2003), SSP-LTP and SSP-LTD may be two concomitant mechanisms that enhance the contrast between previously potentiated and depressed synapses. Thus, during slowwave sleep, a differential bidirectional rescaling of cortical synapses is more likely than the hypothesized unidirectional downscaling (Tononi and Cirelli, 2003). A similar mechanism might also play a role in the cell assembly consolidation between primary sensory cortices and hippocampus during spindle-ripple sequences (Sirota et al., 2003) or in the dialogue between hippocampus and prefrontal cortex during ripple-spindle discharges (Siapas and Wilson, 1998) and thereby contribute to the observed after-sleep strengthening of spatial memories (Peigneux et al., 2004). Because we investigated two idealized conditions of neurons firing synchronously or in isolation, spindle-associated synaptic plasticity may turn out to be more subtle in cases when cells are synchronized only partially. 
Another intriguing finding is the involvement of L-type $\mathrm{Ca}^{2+}$ channels for SSP-LTP, because this $\mathrm{Ca}^{2+}$ channel subtype is specifically linked to the activation of transcription factors and hence to gene expression (Dolmetsch et al., 2001). It has been hypothesized that slow-wave sleep may induce the transcription of genes that are involved in stabilizing changes in synaptic strength (Ribeiro et al., 2004). In agreement, LTP involving L-type $\mathrm{Ca}^{2+}$ channels has been shown previously to last over a period of several days (Borroni et al., 2000); therefore, SSP-LTP could constitute a first step in converting activity-dependent synaptic modifications into more permanent forms as required for a consolidation mechanism.

\section{References}

Achermann P, Borbély AA (1997) Low-frequency $(<1 \mathrm{~Hz})$ oscillations in the human sleep electroencephalogram. Neuroscience 81:213-222.

Akaike N, Hattori K, Oomura Y, Carpenter DO (1985) Bicuculline and picrotoxin block gamma-aminobutyric acid-gated $\mathrm{Cl}^{-}$conductance by different mechanisms. Experientia 41:70-71.

Allen CB, Celikel T, Feldman DE (2003) Long-term depression induced by sensory deprivation during cortical map plasticity in vivo. Nat Neurosci 6:291-299.

Amzica F, Steriade M (1995) Disconnection of intracortical synaptic linkages disrupts synchronization of a slow oscillation. J Neurosci 15:4658-4677.

Amzica F, Steriade M (1997) The K-complex: its slow ( $<1-\mathrm{Hz})$ rhythmicity and relation to delta waves. Neurology 49:952-959.

Artola A, Bröcher S, Singer W (1990) Different voltage-dependent thresholds for inducing long-term depression and long-term potentiation in slices of rat visual cortex. Nature 347:69-72.

Bazhenov M, Timofeev I, Steriade M, Sejnowski TJ (1998) Computational models of thalamocortical augmenting responses. J Neurosci 18:6444-6465.

Benington JH, Frank MG (2003) Cellular and molecular connections between sleep and synaptic plasticity. Prog Neurobiol 69:71-101.

Bhalla US (2002) Biochemical signaling networks decode temporal patterns of synaptic input. J Comput Neurosci 13:49-62.

Birtoli B, Ulrich D (2004) Firing mode-dependent synaptic plasticity in rat neocortical pyramidal neurons. J Neurosci 24:4935-4940.

Borroni AM, Fichtenholtz H, Woodside BL, Teyler TJ (2000) Role of voltage-dependent calcium channel long-term potentiation (LTP) and NMDA LTP in spatial memory. J Neurosci 20:9272-9276.

Buzsáki G (1998) Memory consolidation during sleep: a neurophysiological perspective. J Sleep Res 7 [Suppl 1]:17-23.

Castro-Alamancos MA, Connors BW (1996) Cellular mechanisms of the augmenting response: short-term plasticity in a thalamocortical pathway. J Neurosci 16:7742-7756.

Clemens Z, Fabó D, Halász P (2005) Overnight verbal memory retention correlates with the number of sleep spindles. Neuroscience 132:529-535.

Contreras D, Steriade M (1995) Cellular basis of EEG slow rhythms: a study of dynamic corticothalamic relationships. J Neurosci 15:604-622.

Contreras D, Steriade M (1996) Spindle oscillation in cats: the role of corticothalamic feedback in a thalamically generated rhythm. J Physiol (Lond) 490:159-179.

Contreras D, Destexhe A, Steriade M (1997) Intracellular and computational characterization of the intracortical inhibitory control of synchronized thalamic inputs in vivo. J Neurophysiol 78:335-350.

DeKoninck P, Schulman H (1998) Sensitivity of CaM kinase II to the frequency of $\mathrm{Ca}^{2+}$ oscillations. Science 279:227-230.

Destexhe A, Contreras D, Steriade M (1999) Spatiotemporal analysis of local field potentials and unit discharges in cat cerebral cortex during natural wake and sleep states. J Neurosci 19:4595-4608.

Dobrunz LE, Stevens CF (1999) Response of hippocampal synapses to natural stimulation patterns. Neuron 22:157-166.

Dolmetsch RE, Pajvani U, Fife K, Spotts JM, Greenberg ME (2001) Signaling to the nucleus by an L-type calcium channel-calmodulin complex through the MAP kinase pathway. Science 294:333-339.

Frank MG, Issa NP, Stryker MP (2001) Sleep enhances plasticity in the developing visual cortex. Neuron 30:275-287.
Froemke RC, Dan Y (2002) Spike-timing-dependent synaptic modification induced by natural spike trains. Nature 416:433-438.

Fusi S (2002) Hebbian spike-driven synaptic plasticity for learning patterns of mean firing rates. Biol Cybern 87:459-470.

Gais S, Plihal W, Wagner U, Born J (2000) Early sleep triggers memory for early visual discrimination skills. Nat Neurosci 3:1335-1339.

Gais S, Mölle M, Helms K, Born J (2002) Learning-dependent increases in sleep spindle density. J Neurosci 22:6830-6834.

Grover LM, Teyler TJ (1990) Two components of long-term potentiation induced by different patterns of afferent activation. Nature 347:477-479.

Hobson JA, Pace-Schott EF (2002) The cognitive neuroscience of sleep: neuronal systems, consciousness and learning. Nat Rev Neurosci 3:679-693.

Huber R, Ghilardi MF, Massimini M, Tononi G (2004) Local sleep and learning. Nature 430:78-81.

Koester HJ, Sakmann B (1998) Calcium dynamics in single spines during coincident pre- and postsynaptic activity depend on relative timing of back-propagating action potentials and subthreshold excitatory postsynaptic potentials. Proc Natl Acad Sci USA 95:9596-9601.

Lisman J (1989) A mechanism for the Hebb and the anti-Hebb processes underlying learning and memory. Proc Natl Acad Sci USA 86:9574-9578.

Malenka RC (1991) Postsynaptic factors control the duration of synaptic enhancement in area CAl of the hippocampus. Neuron 6:53-60.

Markram H, Helm PJ, Sakmann B (1995) Dendritic calcium transients evoked by single back-propagating action potentials in rat neocortical pyramidal neurons. J Physiol (Lond) 485:1-20.

Massimini M, Huber R, Ferrarelli F, Hill S, Tononi G (2004) The sleep slow oscillation as a traveling wave. J Neurosci 24:6862-6870.

Mednick S, Nakayama K, Cantero JL, Atienza M, Levin AA, Pathak N, Stickgold R (2002) The restorative effect of naps on perceptual deterioration. Nat Neurosci 5:677-681.

Mölle M, Marshall L, Gais S, Born J (2002) Grouping of spindle activity during slow oscillations in human non-rapid eye movement sleep. J Neurosci 22:10941-10947.

Mölle M, Marshall L, Gais S, Born J (2004) Learning increases human electroencephalographic coherence during subsequent slow sleep oscillations. Proc Natl Acad Sci USA 101:13963-13968.

Peigneux P, Laureys S, Fuchs S, Collette F, Perrin F, Reggers J, Phillips C, Degueldre C, Del Fiore G, Aerts J, Luxen A, Maquet P (2004) Are spatial memories strengthened in the human hippocampus during slow wave sleep? Neuron 44:535-545.

Ribeiro S, Gervasoni D, Soares ES, Zhou Y, Lin SC, Pantoja J, Lavine M, Nicolelis MA (2004) Long-lasting novelty-induced neuronal reverberation during slow-wave sleep in multiple forebrain areas. PLoS Biol 2:126-137.

Rioult-Pedotti M-S, Friedman D, Donoghue JP (2000) Learning-induced LTP in neocortex. Science 290:533-536.

Rosanova M, Timofeev I (2005) Neuronal mechanisms mediating the variability of somatosensory evoked potentials during sleep oscillations in cats. J Physiol (Lond) 562:569-582.

Sejnowski TJ, Destexhe A (2000) Why do we sleep? Brain Res 886:208-223. Siapas AG, Wilson MA (1998) Coordinated interactions between hippocampal ripples and cortical spindles during slow-wave sleep. Neuron 21:1123-1128.

Sirota A, Csicsvari J, Buhl D, Buzsáki G (2003) Communication between neocortex and hippocampus during sleep in rodents. Proc Natl Acad Sci USA 100:2065-2069.

Steriade M, Timofeev I (2003) Neuronal plasticity in thalamocortical networks during sleep and waking oscillations. Neuron 37:563-576.

Steriade M, Nuñez A, Amzica F (1993a) A novel slow ( $<1 \mathrm{~Hz}$ ) oscillation of neocortical neurons in vivo: depolarizing and hyperpolarizing components. J Neurosci 13:3252-3265.

Steriade M, Nuñez A, Amzica F (1993b) Intracellular analysis of relations between the slow $(<1 \mathrm{~Hz})$ neocortical oscillation and other sleep rhythms of the electroencephalogram. J Neurosci 13:3266-3283.

Steriade M, Contreras D, Curró Dossi R, Nuñez A (1993c) The slow $(<1$ $\mathrm{Hz}$ ) oscillation in reticular thalamic and thalamocortical neurons: scenario of sleep rhythm generation in interacting thalamic and neocortical networks. J Neurosci 13:3284-3299.

Steriade M, Contreras D, Amzica F (1994) Synchronized sleep oscillations and their paroxysmal developments. Trends Neurosci 17:199-208. 
Steriade M, Timofeev I, Grenier F, Dürmüller N (1998) Role of thalamic and cortical neurons in augmenting responses and self-sustained activity: dual intracellular recordings in vivo. J Neurosci 18:6425-6443.

Steriade M, Timofeev I, Grenier F (2001) Natural waking and sleep states: a view from inside neocortical neurons. J Neurophysiol 85:1969-1985.

Stuart GJ, Dodt H-U, Sakmann B (1993) Patch-clamp recordings from the soma and dendrites of neurons in brain slices using infrared video microscopy. Pflügers Arch 423:511-518.

Timofeev I, Grenier F, Bazhenov M, Sejnowski TJ, Steriade M (2000) Origin of slow cortical oscillations in deafferented cortical slabs. Cereb Cortex 10:1185-1199.

Timofeev I, Grenier F, Bazhenov M, Houweling AR, Sejnowski TJ, Steriade M (2002) Short- and medium-term plasticity associated with augmenting responses in cortical slabs and spindles in intact cortex of cats in vivo. J Physiol (Lond) 542:583-598.

Tononi G, Cirelli C (2003) Sleep and synaptic homeostasis: a hypothesis. Brain Res Bull 62:143-150.

Villarreal DM, Do V, Haddad E, Derrick BE (2002) NMDA receptor antag- onists sustain LTP and spatial memory: active processes mediate LTP decay. Nat Neurosci 5:48-52.

Walker MP, Stickgold R (2004) Sleep-dependent learning and memory consolidation. Neuron 44:121-133.

Walker MP, Brakefield T, Morgan A, Hobson JA, Stickgold R (2002) Practice with sleep makes perfect: sleep-dependent motor skill learning. Neuron 35:205-211.

Waters J, Helmchen F (2004) Boosting of action potential backpropagation by neocortical network activity in vivo. J Neurosci 24:11127-11136.

Werk CM, Harbour VL, Chapman CA (2005) Induction of long-term potentiation leads to increased reliability of evoked neocortical spindles in vivo. Neuroscience 131:793-800.

Williams SR, Stuart GJ (1999) Mechanisms and consequences of action potential burst firing in rat neocortical pyramidal neurons. J Physiol (Lond) 521:468-482.

Williams SR, Stuart GJ (2000) Backpropagation of physiological spike trains in neocortical pyramidal neurons: implications for temporal coding in dendrites. J Neurosci 20:8238-8246. 